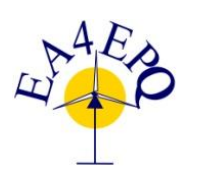

International Conference on Renewable Energies and Power Quality (ICREPQ'13)

Bilbao (Spain), $20^{\text {th }}$ to $22^{\text {th }}$ March, 2013

ORenewable Energy and Pourer Qualily. Gournal (RE\&PQJ)

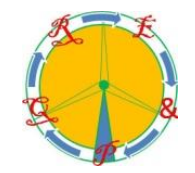

ISSN 2172-038 X, No.11, March 2013

\title{
DESIGN AND TESTING OF A SOLAR PARABOLIC CONCENTRATING COLLECTOR
}

\author{
Eltahir Ahmed Mohamed \\ Mech. Engineering Department, University of Nyala, Sudan \\ Email: Tahir_a m@yahoo.com
}

Phone: +249-9122-70841

\begin{abstract}
This paper is concerned with an experimental study of a simple parabolic trough solar collector tested under the local climatic condition. It presents the collectors' performance and the temperature effective length of the concentrator. A small scale parabolic trough was fabricated with the local available materials using stainless steel sheets as parabolic reflector and galvanized steel pipe as the receiver. As a part of solar technology distribution in Darfur Region, this model is designed erected under the supervision of the Energy Research Center of the University of Nyala (ERCUN). The collector is designed with simple parabolic equations. It was out door tested at the Mechanical Department roof of Nyala University at latitude $12.1^{\circ} \mathrm{N}$, longitude $24.9^{\circ} \mathrm{E}$, and $67 \mathrm{~m}$ elevation. It was East-West oriented to avoid tracking process. The heat transfer fluid (water) was naturally circulated from a header tank. From the experiments, the temperature of the heat transfer fluid was become steady after 82 percent of the total trough length. From the test result and the collectors' performance, the model is seen fairly acceptable for thermal processes. Physical output indicates that by using envelope evacuated glass, high quality steam can be produce for efficient electricity generation.
\end{abstract}

\section{Keywords}

parabolic trough, solar collector, Nyala, Darfur, performance

\section{Introduction}

Sudan is one of the largest countries in Africa and the Middle East Region with an area of about 1,882,000 $\mathrm{km}^{2}$. Energy shortage has become one of the major problems in many regions of the country. Most of these regions are still not access to National Electricity Grid (NEG). Accordingly solar thermal systems became one of the most attractive solutions for these problems. Parabolic trough collectors (PTCs) are currently the most proven solar thermal technology for solar steam generation since high temperature can be obtained without any serious degradation of the collector efficiency. Out of these regions, Darfur Region at the far Western Side of the country is the most one in need for such energy systems. Researchers and engineers tried to optimize the solar energy utilization based on the solar energy parameters. The paper focuses on the effective length of the PTC as one of these parameters depends on the mass flow rate. Since collectors' efficiency depends on the solar insolation and ambient weather condition, the collector performance depending on these parameters is investigated. From the results of this parameter, other similar system can be optimized. A simple parabolic trough collector is designed, fabricated and tested. The results of the test for this simple system, both efficiency and performance obtained characteristics is considerably lower than that of typical collectors which can be attributed to the high thermal losses of the collector. 


\section{Collector design}

\subsection{Trough design}

From the standard available reflective stainless steel sheets, a pilot trough-receiver unit is developed. Stainless steel sheet $2.4 \mathrm{mx} 1.2 \mathrm{~m}$ was chosen as reflecting surface.. The collector is designed with simple parabolic equations. From geometrical relations of the parabolic section, equations (1), the cross section for the parabolic trough was traced as shown by figures.1. The sheet was curved to form a parabolic trough module of $2.4 \mathrm{~m}$ length and $1 \mathrm{~m}$ aperture width with effective aperture area of $2.4 \mathrm{~m}^{2}$. the simple parabolic equation in Cartesian coordinates is,

$$
x^{2}=4 f y
$$

From equation (1), the height of the parabola in terms of the focal length and aperture diameter is:

$$
(\mathrm{a} / 2) 2=4 \mathrm{f} \mathrm{h}
$$

Or:

$$
h=\frac{a^{2}}{16 f}
$$

The rime angle $\psi_{\text {rim }}$ is given by:

$$
\tan \frac{\psi_{\text {rim }}}{2}=\frac{a}{4 f}
$$

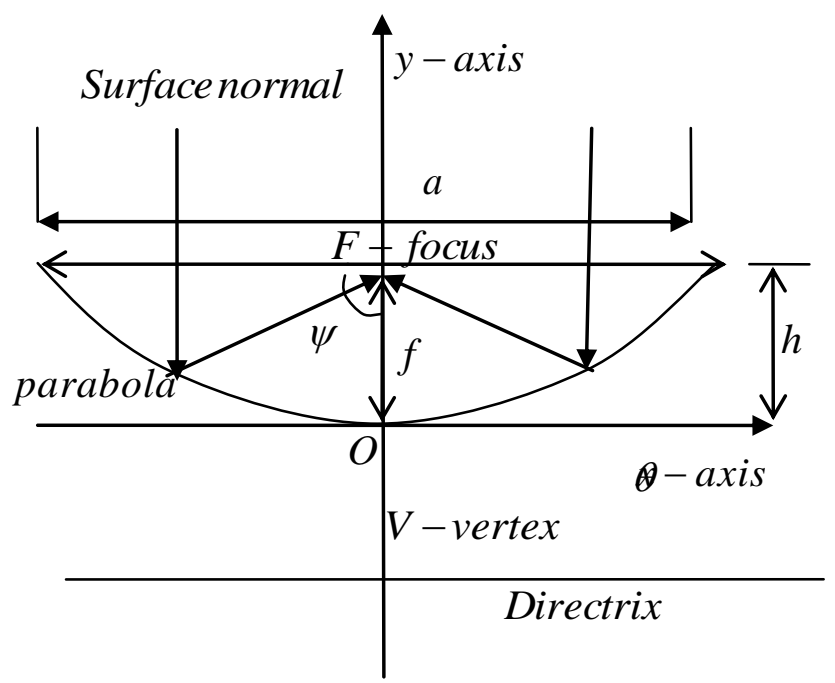

Fig. 1 The schematic of the collector
Geometrical concentration ratio $\mathrm{Cg}$ is defined as "the area of the collector aperture $A_{a}$, divided by the surface area of the receiver $A_{r}$.

$$
C_{g}=\frac{A_{a}}{A_{r}}
$$

From the selected values of the concentration ratio and the ratio between the concentrator length to its aperture width, the values of the aperture area, the receiver surface area, the aperture width, the receiver outside diameter, and the length of the concentrator were calculated from equation (1) \& (3). For this model the focal point is selected at the aperture line i.e, the collector height $h$ is equal to the focal length $f$ with rim angle $90^{\circ}$. The selected data of the designed model has the following values as given by table 1 .

Table 1- Geometrical data of the parabolic trough model

\begin{tabular}{|l|l|l|}
\hline Item & Sample & Value \\
\hline Length & $\mathrm{L}$ & $2.4 \mathrm{~m}$ \\
\hline Aperture & $a$ & $1 \mathrm{~m}$ \\
\hline Rim angle & $\psi$ & $90 \mathrm{o}$ \\
\hline Focal length & $f$ & $0.25 \mathrm{~m}$ \\
\hline Receiver diameter & $\mathrm{d}$ & $3.8 \mathrm{~cm}$ \\
\hline Geometrical C.R & $C_{g}$ & 26.3 \\
\hline The concentrator height & $h$ & $0.25 \mathrm{~m}$ \\
\hline
\end{tabular}

\subsection{Collector supporting structure}

For collectors' stability and accuracy, a rigid supporting structure is designed. The structure frame is supported to the rotation axis of the parabolic reflecting surface. It used for the rotation of the horizontal axis for daily tracking of the sun. For test purpose and cost reduction, the unit is designed for easy manual tracking. 


\subsection{The receiver}

The receiver pipe is selected from the available local pipes. Although the galvanized steel is relatively low absobtivity, it is selected as the collector absorber as only available pipe at moment of design and test. A pipe of $2.54 \mathrm{~cm}$ inner diameter and 3.8 outer diameters is used. It is acceptable according to the aperture width to give geometrical concentration ratio of 26.3 , according to the limitation of the collectors' parameters and common practice such as piping, fluid velocity, fabrication and heat loss. The collector is fixed East-West direction so that the direct solar beam reflected to the absorber throughout the day without tracking. It needs daily adjusting the sun motion. The absorber is coated with black color.

\subsection{The reflecting surface}

The collectors reflecting surface is curved in a parabolic shape that linearly extended into trough shape to form curve area of $2.88 \mathrm{~m}^{2}$ and aperture area of $2.4 \mathrm{~m}^{2}$.

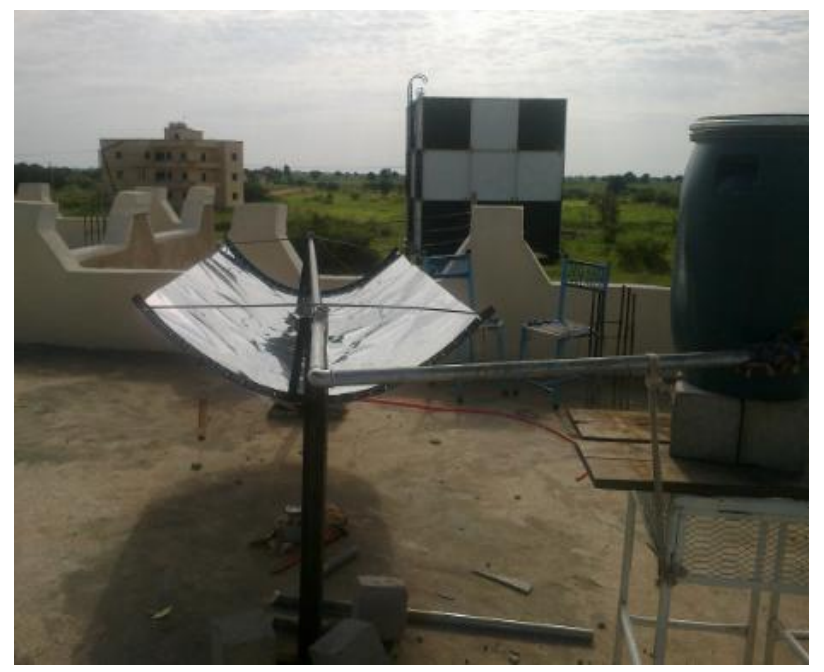

Fig.2 The solar collector setup

\section{Experimental setup}

The experimental setup for testing the collector consists of the constructed collector, 96liters storage tank, and throttling valve. The storage tank is fixed above the receivers' pipe level to allow the heating fluid to flow naturally without pumping system. The storage tank is filled from main water supply and flow is done in an open system. The water inlet and outlet of the absorber tube, the water flow rate and the solar radiation intensity are continually measured during the experiment. The test was carried outdoor during September and October 2012. The testing system is orient as showed by fig. 2 .
The solar efficiency is estimated by equation (6).

$$
\eta_{c}=\frac{\dot{m}_{w} c_{w}\left(T_{o}-T_{i}\right)}{I_{b} \cdot A}
$$

Where:

To, $\mathrm{Ti}=$ inlet a outlet water temperature respectively $-{ }^{\circ} \mathrm{C}$

$\mathrm{m}_{\mathrm{w}}=$ waters' mass flow rate $-\mathrm{kg} / \mathrm{s}$

$\mathrm{c}_{\mathrm{w}}=$ the specific heat of water $\mathrm{kJ} / \mathrm{kg} .{ }^{\circ} \mathrm{C}$

$\mathrm{I}_{\mathrm{b}}=$ direct solar beam $=\mathrm{W} / \mathrm{m}^{2}$

$\mathrm{A}=$ aperture area $=\mathrm{m}^{2}$

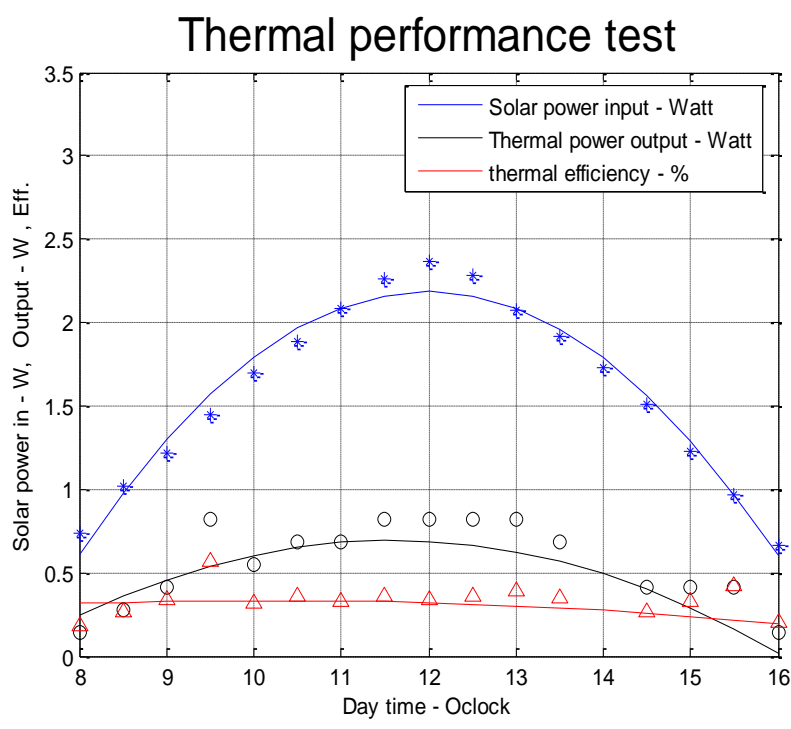

Fig. 3 The thermal performance of the collector

The test was repeated with 4 water flow rates, from which the heating performance and temperature effective length of the receivers' pipe were evaluated. Fig. 3 shows the heating performance at optimum flow rate of 0.048 $\mathrm{kg} / \mathrm{sec}$. The average and maximum efficiency of the system is found to be $37 \%$ and $42 \%$ respectively. The maximum efficiency is given at $0.048 \mathrm{~kg} / \mathrm{sec}$. The effective length of the collector, from the LMTD values is found similar for all flow rates, even though LMTD values changed from maximum value of $36.5^{\circ} \mathrm{C}$ and minimum value of $25.5^{\circ} \mathrm{C}$. Equations (7) to (10) give mathematical models for the LMTD at the 4 measured flow rates from minimum to maximum respectively. 


$$
\begin{aligned}
& y=40.162+15 . .056 x-1.741 x^{2} \\
& y=31.531+16.579 x-1.573 x^{2} \\
& y=32.260+13.176 x-1.487 x^{2} \\
& y=36.500+5.740 x-0.107 x^{2}
\end{aligned}
$$

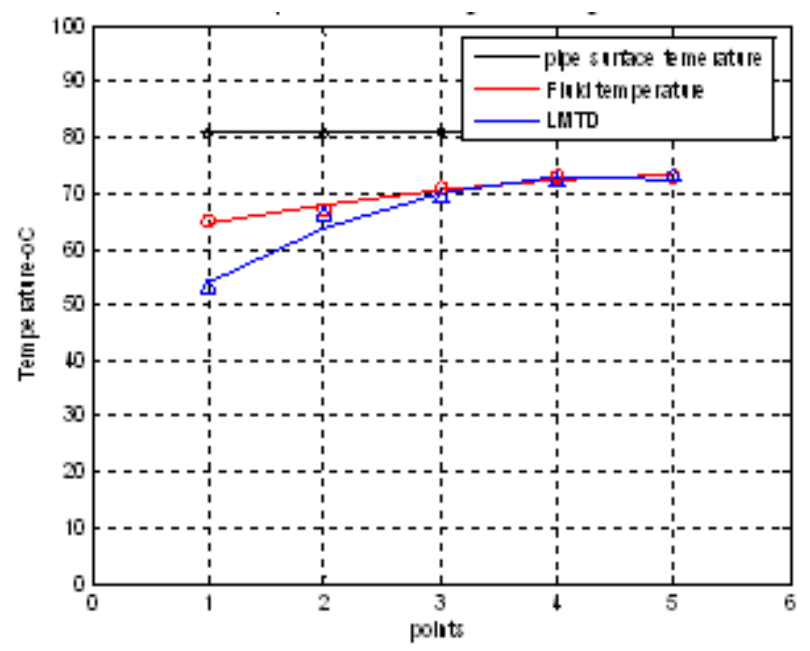

Figure 4. The characteristic curve of LMTD at flow rate $0.025 \mathrm{~kg} / \mathrm{sec}$

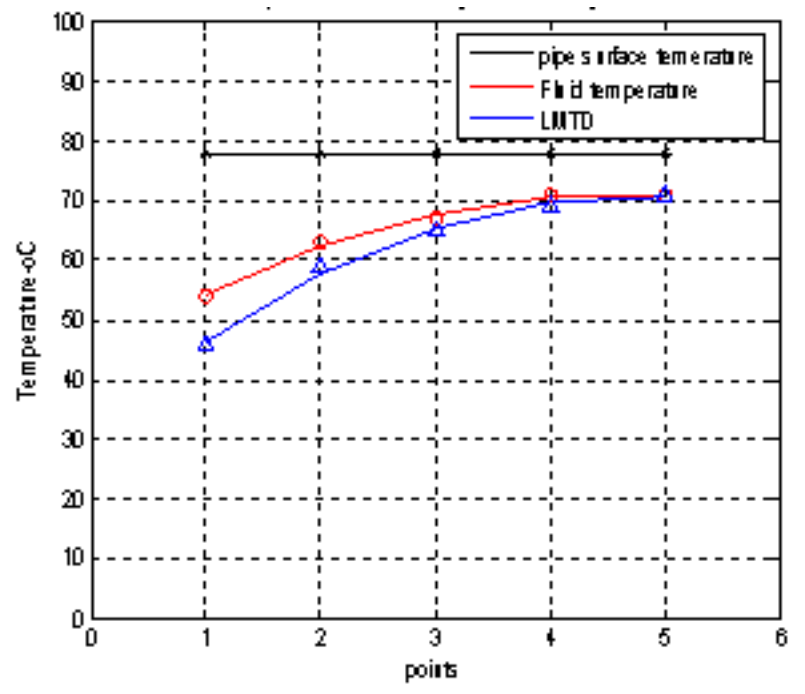

Figure 5. The characteristic curve of LMTD at flow rate $0.032 \mathrm{~kg} / \mathrm{sec}$

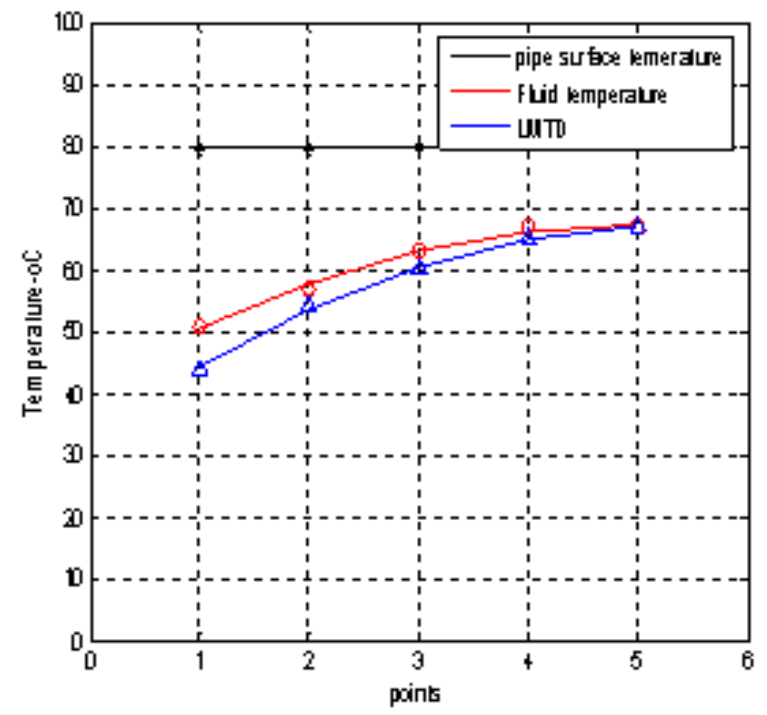

Figure 6 The characteristic curve of LMTD at flow rate $0.048 \mathrm{~kg} / \mathrm{sec}$

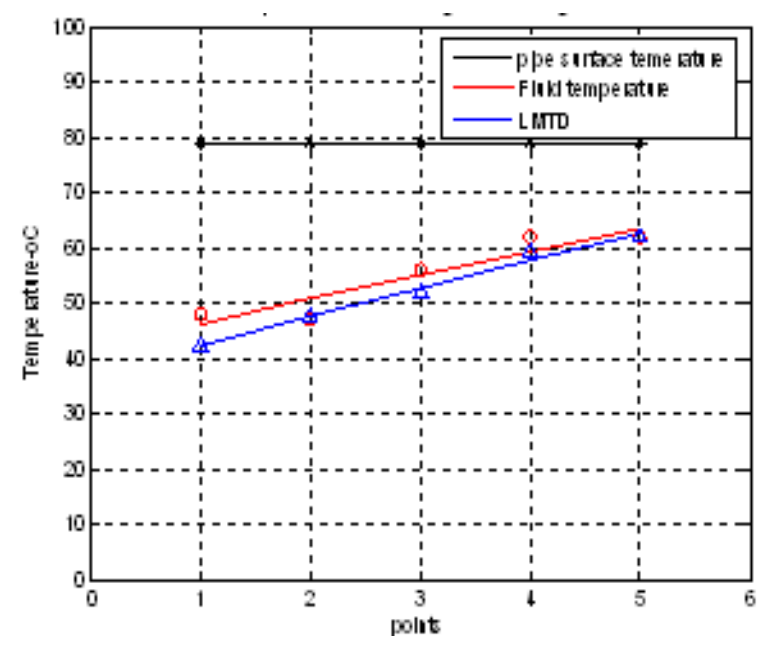

Figure 7 The characteristic curve of LMTD at flow rate $0.062 \mathrm{~kg} / \mathrm{sec}$

\section{Results}

From the test results, the collector and the receiver can be optimized to the required length for selected power required. Since the concentration ratio is one of the parameters affect the collectors' performance, and the experiment is carried on one concentration ratio, other concentration ratios are to be reconsidered to find an optimization again. However this experiment is tested under east-west orientation which causes solar radiation end losses at early and late day hours. To counteract this 
problem, the configuration of the collector can be changed to N-S orientation. This will allow operation with tracking system in such a way that most of the concentrated rays are intercepted by the receiver and the performance probably changed. The average collector efficiency is about $37 \%$ which is fairly acceptable. Using evacuated glass envelop around the absorbing tube and using stainless steel pipes in state of galvanized pipes will improve the collectors performance, considering that this is the first attempt to manufacture such collector locally.

\section{References}

[1] William B. Stine and Michael Geyer. Power From The Sun - www-Powerfromthesun.net/book. htm-12k. 2001.

[2] John A. Duffie and William A. Beckman - Solar Engineering of Thermal Process - WILEY - JAHN WILY \& SONS INC Third Edition - October 2005.

[3] R. Forristall - Heat Transfer Analysis and Modeling of a Parabolic Trough Receiver Implemented in Engineering
Equation Solver - National Renewable Energy Laboratory - USA Department of Energy October 2003

[4] Jell C. Anderson, William Carey. Conceptual Design of Solar Powered Desalination Using Parabolic Mirrors. Boston University - summer 2002.

[5] M. J. Brooks, I. Mills, T. M. Harms - Performance of a parabolic trough solar collector. - Journal of Engineering in Southern Africa - Vol. 17 August 2006

[6] S. Fisher, H. Muller-Stein Hagen - Collector Testing Method Under Quasi-Dynamic Condition According to the European Standard EN 1297S-2 - Germany

[7] Eltahir A. M. Design, Construction and testing of a Parabolic Trough Solar Collector fo Electricity Generation in Sudan PHD Thesis, U. of K. 2011

[8] Henry W. Price \& Stephen Carpenter. The Potential for lowCost Concentrating Solar Power Systems NREL National Renewable Energy Laboratory U.S. Department of Energy Laboratory. August 1-5, 1999

[9] Manoon Pidhnwan, Sombul Teckansap, and Joseph Khedare - The Effective Length of Solar Parabolic Concentrator Collector - The Joint International Conference on Sustainable Energy and Environment (SEE), 1-3 Decemper 2004Hun Hin ,Thailand 